NASA/TM-2003-212613

\title{
Catalyzed Combustion of Bipropellants for Micro-Spacecraft Propulsion
}

Steven J. Schneider

Glenn Research Center, Cleveland, Ohio

Chih-Jen Sung and George A. Boyarko

Case Western Reserve University, Cleveland, Ohio 
Since its founding, NASA has been dedicated to the advancement of aeronautics and space science. The NASA Scientific and Technical Information (STI) Program Office plays a key part in helping NASA maintain this important role.

The NASA STI Program Office is operated by Langley Research Center, the Lead Center for NASA's scientific and technical information. The NASA STI Program Office provides access to the NASA STI Database, the largest collection of aeronautical and space science STI in the world. The Program Office is also NASA's institutional mechanism for disseminating the results of its research and development activities. These results are published by NASA in the NASA STI Report Series, which includes the following report types:

- $\quad$ TECHNICAL PUBLICATION. Reports of completed research or a major significant phase of research that present the results of NASA programs and include extensive data or theoretical analysis. Includes compilations of significant scientific and technical data and information deemed to be of continuing reference value. NASA's counterpart of peerreviewed formal professional papers but has less stringent limitations on manuscript length and extent of graphic presentations.

- TECHNICAL MEMORANDUM. Scientific and technical findings that are preliminary or of specialized interest, e.g., quick release reports, working papers, and bibliographies that contain minimal annotation. Does not contain extensive analysis.

- CONTRACTOR REPORT. Scientific and technical findings by NASA-sponsored contractors and grantees.
- CONFERENCE PUBLICATION. Collected papers from scientific and technical conferences, symposia, seminars, or other meetings sponsored or cosponsored by NASA.

- SPECIAL PUBLICATION. Scientific, technical, or historical information from NASA programs, projects, and missions, often concerned with subjects having substantial public interest.

- TECHNICAL TRANSLATION. Englishlanguage translations of foreign scientific and technical material pertinent to NASA's mission.

Specialized services that complement the STI Program Office's diverse offerings include creating custom thesauri, building customized databases, organizing and publishing research results ... even providing videos.

For more information about the NASA STI Program Office, see the following:

- Access the NASA STI Program Home Page at http://www.sti.nasa.gov

- E-mail your question via the Internet to help@sti.nasa.gov

- Fax your question to the NASA Access Help Desk at 301-621-0134

- Telephone the NASA Access Help Desk at 301-621-0390

- Write to:

NASA Access Help Desk

NASA Center for AeroSpace Information 7121 Standard Drive

Hanover, MD 21076 
NASA/TM-2003-212613

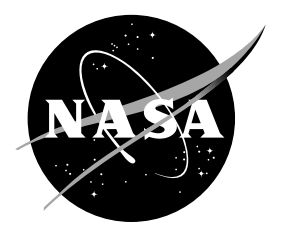

\section{Catalyzed Combustion of Bipropellants for Micro-Spacecraft Propulsion}

Steven J. Schneider

Glenn Research Center, Cleveland, Ohio

Chih-Jen Sung and George A. Boyarko

Case Western Reserve University, Cleveland, Ohio

Prepared for the

39th Joint Propulsion Conference and Exhibit

cosponsored by the AIAA, ASME, SAE, and ASEE

Huntsville, Alabama, July 20-23, 2003

National Aeronautics and

Space Administration

Glenn Research Center 
Available from

NASA Center for Aerospace Information 7121 Standard Drive

Hanover, MD 21076
National Technical Information Service 5285 Port Royal Road Springfield, VA 22100

Available electronically at http://gltrs.grc.nasa.gov 


\title{
Catalyzed Combustion of Bipropellants for Micro-Spacecraft Propulsion
}

\author{
Steven J. Schneider ${ }^{*}$ \\ National Aeronautics and Space Administration \\ Glenn Research Center \\ Cleveland, Ohio 44135 \\ Chih-Jen Sung ${ }^{\dagger}$ and George A. Boyarko ${ }^{\S}$ \\ Case Western Reserve University \\ Cleveland, Ohio 44106
}

\begin{abstract}
This paper addresses the need to understand the physics and chemistry involved in propellant combustion processes in micro-scale combustors for propulsion systems on micro-spacecraft. These spacecraft are planned to have a mass less than 50 kilograms with attitude control estimated to be in the 10 milliNewton thrust class. These combustors are anticipated to be manufactured using Micro Electrical Mechanical Systems (MEMS) technology and are expected to have diameters approaching the quenching diameter of the propellants. Combustors of this size are expected to benefit significantly from surface catalysis processes. Miniature flame tube apparatus is chosen for this study because microtubes can be easily fabricated from known catalyst materials and their simplicity in geometry can be used in fundamental simulations for validation purposes. Experimentally, we investigated the role of catalytically active surfaces within 0.4 and $0.8 \mathrm{~mm}$ internal diameter microtubes, with special emphases on ignition processes in fuel rich gaseous hydrogen and gaseous oxygen. Flame thickness and reaction zone thickness calculations predict that the diameters of our test apparatus are below the quenching diameter of the propellants in sub-atmospheric tests. Temperature and pressure rise in resistively heated platinum and palladium microtubes was used as an indication of exothermic reactions. Specific data on mass flow versus preheat temperature required to achieve ignition are presented. With a plug flow model, the experimental conditions were simulated with detailed gas-phase chemistry, thermodynamic properties, and surface kinetics. Computational results generally support the experimental findings, but suggest an experimental mapping of the exit temperature and composition is needed.
\end{abstract}

\section{Introduction}

The need for micro-scale propulsion devices is apparent due to the growing desire to reduce the size and cost of future spacecraft. These spacecraft are planned to have a mass of less than 50 kilograms and require an attitude control estimated to be in the 10 milli-Newton thrust class [1]. NASA Goddard Space Flight Center is currently conducting feasibility studies on formation flying of such spacecraft and the U.S. Air Force is planning on developing 10 to $20 \mathrm{~kg}$ class of spacecraft, defined as "nano-spacecreaft," for use in satellite constellations [2]. Chemical propulsion may have a distinct advantage because hydrocarbon energy densities are 100 times greater than current batteries [3] and the fact that a small amount of electrical energy will be budgeted for propulsion purposes. In order to develop chemical based propulsion for this class of small spacecraft, micro-combustion must be realized. These micro-combustion propulsion devices can be used both for primary thrust and orbit or attitude control. When grouped into arrays for larger thrust applications, they provide for unprecedented propulsive flexibility with a range of thrust levels and steady low-g acceleration. The redundancy of the thrusters and the potential for a spark-less ignition can also provide unmatched reliability. In a more general application, they can be used as igniters for larger rockets. Micro-combustors for power generation currently being researched are

\footnotetext{
* Aerospace Engineer, On-Board Propulsion Branch, Steven.J.Schneider@grc.nasa.gov, Associate Fellow AIAA

$\dagger$ Associate Professor, Department of Mechanical and Aerospace Engineering, cjs15@ po.cwru.edu. Senior Member AIAA.

$\S$ Graduate Student, Department of Mechanical and Aerospace Engineering, gab16@ po.cwru.edu. Student Member AIAA.
} 
predicted to possess energy densities of 10 times that of an existing battery [4].

If combustion is employed as a viable form of propulsion, the devices are anticipated to be manufactured using Micro Electrical Mechanical Systems (MEMS) technology and are expected to have diameters approaching that of the quenching diameter of the propellants. In order to overcome the heat loss to the wall of the combustor, the thruster will need to take advantage of the added benefits of catalytic combustion on the surface of the device. More research on the catalytic effects of different materials on a wide array of common fuels is still needed, especially those which are a high priority of in-situ resource utilization (ISRU) technologies. The overall objective of this study is to explore flammability limits, combustion efficiency, and modeling of propellant combustion over heated catalysts whose geometry approaches or is smaller than the order of flame thickness of the propellant.

Miniature, cylindrical flame tubes on the order of sub-millimeter in size are favorable for investigation in this study because of the simple geometry and relative ease of fabrication. In each case, the entire channel can be fabricated from the catalyst material with minimum effort.

In the following, we will sequentially present the characterization of gaseous $\mathrm{H}_{2} / \mathrm{O}_{2}$ combustion, an overview of catalytic combustion, experimental setup, and computational methodology, which is followed by results and discussion.

Flame Characteristics and Quenching Diameter

Studies of premixed combustion in a tube have shown that if the tube diameter is progressively decreased, the flame eventually cannot propagate $[5,6]$. Thus, the so-called quenching diameter is the critical diameter of the tube below which flame propagation is not possible. This is because diffusion of species and heat transfer from the flame front to the tube wall quenches the reaction. It is also noted that wall quenching affects not only flammability limits, but also ignition phenomena $[5,6]$.

Theoretical analysis has shown that the quenching diameter is on the same order as the flame thickness [5]. The flame thickness represents the overall non-equilibrium processes of reaction and diffusion in the flame, and hence provides an indication of the residence time within the flame. Since the flame thickness is inversely proportional to the burning rate, it decreases with increasing burning intensity. As such, nearstoichiometric flames would have a relatively smaller flame thickness as well as quenching diameter due to stronger burning intensity.

Spatially resolved profiles of temperature and heat release rate for a freely-propagating $\mathrm{H}_{2} / \mathrm{O}_{2}$ flame in the flame coordinate are computed using PREMIX code [7] with detailed chemistry, thermodynamic properties, and transport properties. The $\mathrm{H}_{2} / \mathrm{O}_{2}$ kinetic mechanism is taken from Mueller et al. [8]. Calculations were run for freely propagating $\mathrm{H}_{2} / \mathrm{O}_{2}$ premixed flames under adiabatic and non-adiabatic conditions.

Flame dimensions can be characterized using various methods of analysis. In the first method, a flame thickness, $\delta$, can be obtained by calculating the difference between the final and initial temperatures and dividing by the maximum value of the temperature gradient. A plot of $\mathrm{H}_{2} / \mathrm{O}_{2}$ flame thickness as a function of equivalence ratio for atmospheric pressure and pressure of $34.5 \mathrm{kPa}$ (approximately $5 \mathrm{psia}$ ) is given in fig. 1. As expected, $\delta$ increases with increasing equivalence ratio. It is also seen that flame thickness increases with decreasing pressure and the calculated flame thickness at the test pressure of $34.5 \mathrm{kPa}$ and an equivalence ratio of 10 (mixture ratio $\mathrm{MR}=0.8$ ) is $4 \mathrm{~mm}$, which is greater than the diameter of either the $0.4 \mathrm{~mm}$ platinum or the $0.8 \mathrm{~mm}$ palladium microtubes used in this catalytic micro-combustion experiment.

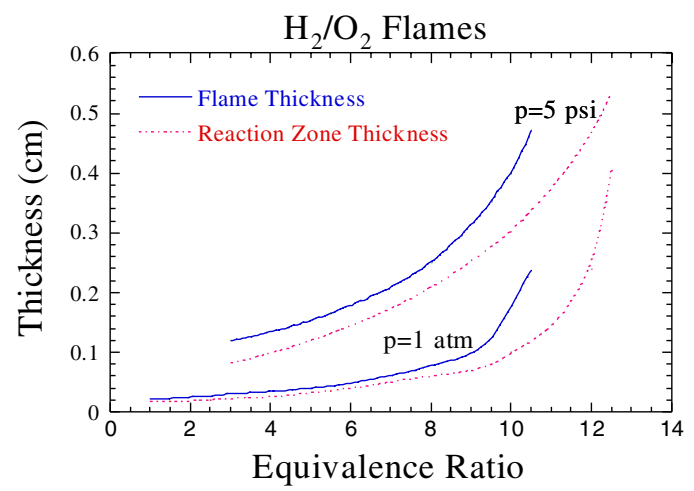

Figure 1. Plot of flame thickness and reaction zone thickness versus equivalence ratio for $\mathrm{p}=1$ atm and 5 psia.

In the second method, we define a reaction zone as the full width of the half maximum of the heat release profile. Figure 1 also shows the corresponding reaction zone thickness. At the equivalence ratio of $10(\mathrm{MR}=0.8)$, the reaction 
zone thickness is $\sim 1 \mathrm{~mm}$ at atmospheric pressure and initial temperature of $300 \mathrm{~K}$ and increases to $\sim 3 \mathrm{~mm}$ when the pressure is reduced to $34.5 \mathrm{kPa}$. Experimental tests in the microtubes were run mostly between 1.2 and 0.4 mixture ratios (equivalence ratios of 6.7 to 20 , respectively). At these mixture ratios and the low pressure of the tests the reaction zone thicknesses are greater than the diameter of either the $0.4 \mathrm{~mm}$ platinum or the $0.8 \mathrm{~mm}$ palladium microtubes used in this catalytic micro-combustion experiment.

In order to determine the flammability limits and capture the extinction turning point, the PREMIX code was modified to include radiative heat loss and the capability of solving the equations at the singular points. When continuing the calculation from the upper (stable) branch to the lower (unstable) branch by passing through the turning point, numerical difficulty, especially with detailed chemistry, is encountered because the Jacobian matrix used in the Newton's method becomes singular at the turning point. To solve this problem, the flame controlling continuation method [9] is employed in this study. Radiative heat loss from $\mathrm{H}_{2} \mathrm{O}$ is considered since it is the primary radiative species in hydrogen flames. The corresponding Planck mean absorption coefficient is a function of temperature and is obtained from Ref. [10]. The analysis was done to test the rich flammability limits of the $\mathrm{H}_{2} / \mathrm{O}_{2}$ flames. Figure 2 shows the variation in the mass burning flux with equivalence ratio at varying pressures. It is seen that the burning flux decreases with increasing equivalence ratio. The turning point, beyond which steady flame propagation is not possible, defines the rich flammability limit.

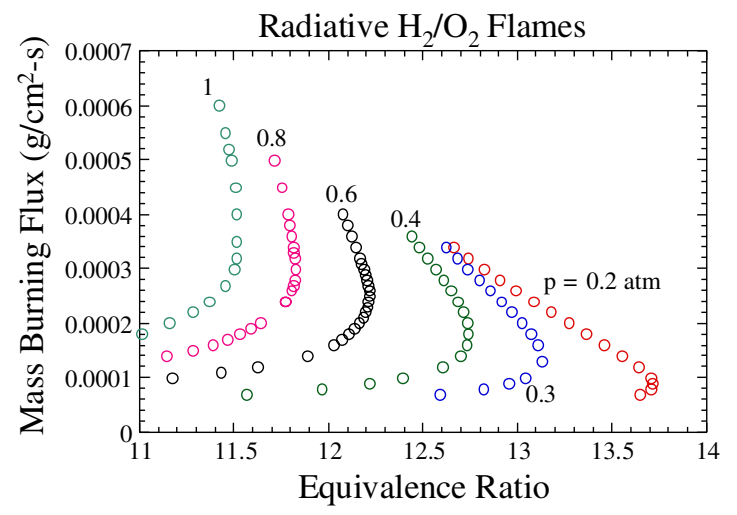

Figure 2. Mass burning flux as a function of equivalence ratio for $\mathrm{H}_{2} / \mathrm{O}_{2}$ flames at various pressures. The turning point of the response curve defines the rich flammability limit.
Calculations also show that the rich limit of the $\mathrm{H}_{2} / \mathrm{O}_{2}$ flame increases with decreasing pressure. We further note that for near rich limit hydrogen flames, in which the Lewis number is greater than unity, pulsating instability has been observed to take place in mixtures with fuel concentrations slightly below that of the rich limit [11-13] and the flame is found to oscillatorily extinguish well ahead of the static extinction limit $[12,13]$. Therefore, the flammability range of a $\mathrm{H}_{2} / \mathrm{O}_{2}$ mixture is expected to be narrowed when the intrinsic oscillatory nature of flame propagation is taken into account.

\section{Overview of Catalytic Combustion}

The principal advantage of using catalysts for primary combustion reactions is their ability to sustain reactions that are well beyond the flammability limit for homogeneous gaseous combustion. During the last three decades, catalysts have been investigated for both augmenting primary heat release in gas turbines and post-combustion treatment of pollutant emission in aircraft, automobile, and power generation applications. For generating power, the focus is on conditions at which catalytic reactions are used to promote the primary combustion reactions.

A heterogeneous catalyst typically adsorbs the reactants and subsequently promotes critical reactions at certain adsorption sites. Surface reactions occur and then the products are desorbed and along with heat are transported into the flow by diffusion, thereby increasing the overall reaction rate.

The reacting flow processes within the catalytic bed are complicated. Take a premixed fuel/air mixture flowing through a long channel with catalytic surfaces as an example [14]. Near the inlet section, the fuel conversion is controlled by the heterogeneous reactions at the surface of the catalyst. In this region, the bulk gas temperatures are typically too low to support homogeneous combustion. After a certain distance downstream of the inlet, the heterogeneous reaction rates increase with increasing temperatures of both near-wall gas and substrate. As the reaction rate increases to an extent, the fuel conversion is no longer controlled by the surface reaction rate. Instead, the fuel consumption is now controlled by the rate at which new gas phase 
reactants are transported to the surface, and the catalytic reactions at the wall will be limited solely by the rate of mass transfer. Further downstream and beyond this diffusion-limited region, thermal runaway of homogeneous or gas phase reactions occur as heat continues to diffuse into the bulk gas flow. These homogeneous reactions are typically initiated at bulk gas temperatures in the range of 1200-1300 K.

Based on the above description, it is imperative to identify how the catalyzed processes scale with the combustor size [15]. In the surface kinetics controlled region, the process is primarily dependent on the catalytic Damköhler number, which is the ratio of system residence time to the characteristic heterogeneous reaction time. For a given residence time, the catalytic Damköhler number is inversely proportional to the combustor size due to the dependence of the heterogeneous reaction rate on surface area [15]. The transition from surface reaction- to diffusion-limited processes and the progression of the latter are expected to scale with the mass transport number that is the ratio of the characteristic residence time of the gas in the reactor to the mass/heat transport time. Since both the heat and mass transfer times scale inversely with the hydraulic diameter, both transport processes are favored when the combustor dimension is reduced, as is the overall progression to the homogeneous reaction region [15].

Therefore, although the increase of the surface to volume ratio of the combustor is problematic for gas phase combustion, it favors catalytic combustion. Despite the catalytic reaction being generally slower than the gas phase reaction, due to the relative increase of surface area and the lower temperature of the catalytic reaction, microcombustors utilizing catalytic combustion may be easier to implement than those utilizing gas phase reactions. In fact, it has been demonstrated [16] using a heat-recirculating engine that with a catalyst located in the combustion volume hydrogen/air mixtures can exhibit thermal runaway at room temperature and butane (or propane) can self-start at less than $500 \mathrm{~K}$.

Many unique technology issues are related to MEMS-based micro-propulsion systems. They include overall issues such as materials selection, fabrication, sealing, assembly, pressurization, testing, and characterization, as well as the combustion related issues. In view of the above discussion the combustor remains one of the most challenging components to miniaturize. Therefore, the fundamental understanding of various micro-combustion phenomena constitutes the long range goal of the present study.

As a first step, the present microtube experiments are simulated based on PLUG code [17] with detailed gas-phase and surface chemistry. In this plug-flow model, it is assumed that there is no mixing in the flow direction, while perfect mixing in the transverse directions. Moreover, axial diffusion of any quantity is negligible relative to the corresponding convective term, which is particularly valid in the present high-speed flow conditions. The computational specifications will be detailed in a later section.

We further note that Raja et al. [18] recently carried out a critical evaluation of Navier-Stokes, boundary-layer, and plug-flow models for reacting flows in a catalytic channel. The range of validity of various approximations was identified through the comparison of the solutions obtained by using three different formulations. While plug-flow models are computationally inexpensive, the range of validity was found to be limited [18]. We will show in due course that the plug-flow approximation is valid in most of the conditions investigated herein, by comparing the competing time scales following the study of Raja et al. [18].

\section{Experimental Setup}

A test stand was arranged so that the flow path of premixed combustible gases was directed inside a microtube, fabricated from catalytic material. $\mathrm{H}_{2} / \mathrm{O}_{2}$ mixtures were used in conjunction with a $0.4 \mathrm{~mm}$ I.D. platinum microtube and a $0.8 \mathrm{~mm}$ I.D. palladium microtube. Miniature flame tubes were chosen for experimentation because of their simplistic geometry that can be used in fundamental simulations as well relative ease of fabrication. The tubes will also be resistively heated with different values of heat flux using a DC power supply. The $0.4 \mathrm{~mm}$ I.D. platinum tube has a length of $100 \mathrm{~mm}$, of which $70 \mathrm{~mm}$ was resistively heated, and a wall thickness of $0.15 \mathrm{~mm}$. The $0.8 \mathrm{~mm}$ I.D. palladium tube has a $190 \mathrm{~mm}$ length, of which $160 \mathrm{~mm}$ was resistively heated, and a $0.1 \mathrm{~mm}$ wall thickness. In both cases, the middle of the tube was resistively heated, leaving the ends on either side to be unheated, with 
$15 \mathrm{~mm}$ on each side. Thermocouples were spot welded at locations of 20,50 , and $80 \%$ of full length on the outer surface of the heated section of the tubes. The entire test apparatus consists of the microtube, a mass flow control system, electrical power supply, and data acquisition system. Schematics and photograph are shown in figs. 3 and 4 respectively. The test apparatus is then located inside a vacuum test cell located at NASA Glenn Research Center, which can maintain an ambient pressure of $1.38 \mathrm{kPa}$ (10 torr).

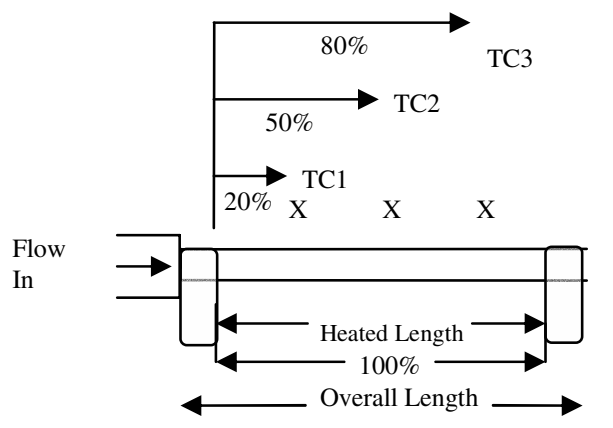

X - Marks Thermocouple Locations

Figure 3. Schematic of microtube test articles.

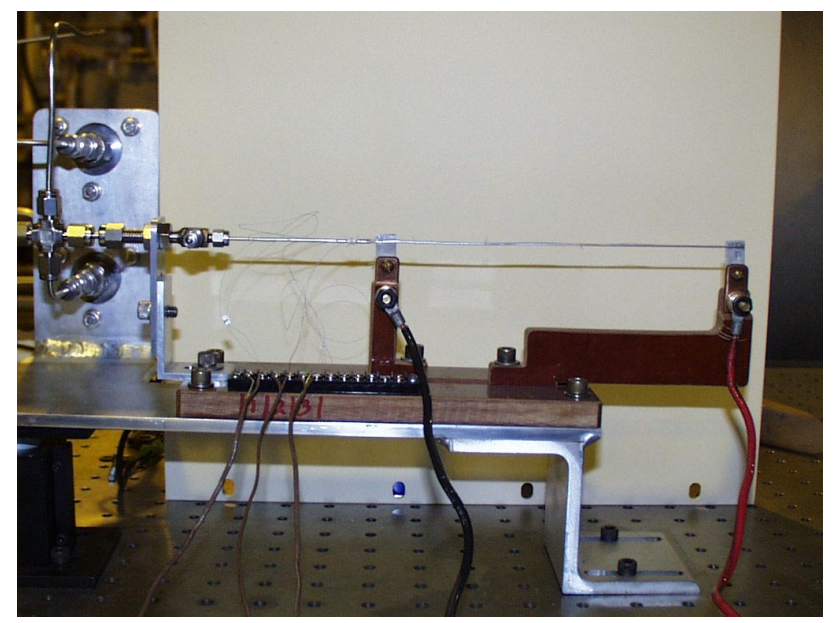

Figure 4. Microtube test apparatus (0.8 mm I.D.).

Low mixture ratios (high equivalence ratios) were tested to explore the fuel rich flammability limits of the propellants. Fuel rich conditions were selected to avoid melting of the catalyst and oxidation loss of catalyst material. Each of these chemicals is non-toxic and can be produced in orbit by water electrolysis [19]. Detailed gas chemistry, thermodynamic properties, transport properties, and surface kinetics for $\mathrm{H}_{2} / \mathrm{O}_{2} / \mathrm{Pt}$ and $\mathrm{H}_{2} / \mathrm{O}_{2} / \mathrm{Pd}$ systems are also available for numerical simulations.

\section{Computational Methodology}

Figure 5 shows the microtube configuration used in the simulations, where $U$ is the inlet velocity, $\mathrm{L}$ the tube length, and $\mathrm{D}$ the tube diameter. The plug flow reactor is modeled to be an empty tube with a negligible wall thickness. Part of the tube is resistively heated with uniform heat flux $\mathrm{Q}$, while the first section of length $\ell_{1}$ and the end section of length $\ell_{2}$ are not heated. Governing equations for solving the steady-state plug flow reactor is listed below.

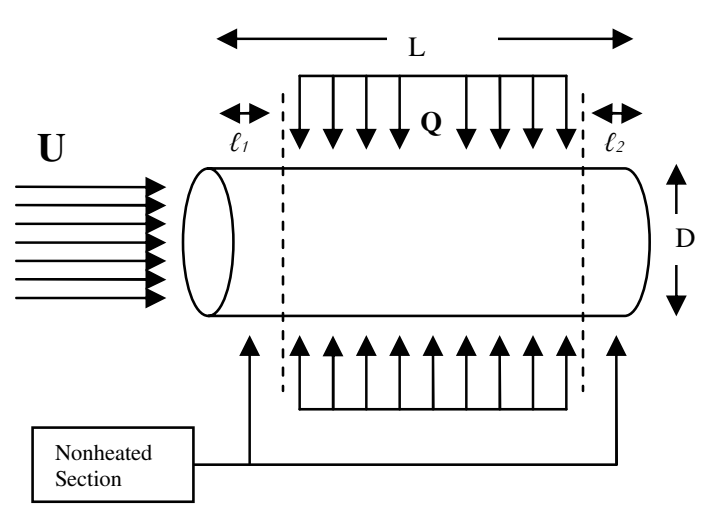

Figure 5. Computational configuration of microtube.

Continuity:

$\rho A \frac{d u}{d x}+u A \frac{d \rho}{d x}=a \sum_{g a s}^{K_{g}} \dot{g}_{k} W_{k}$

Species:

$\rho u A \frac{d Y_{k}}{d x}+Y_{k} a \sum_{g a s}^{K_{g}} \dot{g}_{k} W_{k}=W_{k}\left(\dot{g}_{k} a+\dot{\omega}_{k} A\right)$

Energy:

$\rho u A\left(\sum_{\text {gas }}^{K_{g}} h_{k} \frac{d Y_{k}}{d x}+\bar{C}_{p} \frac{d T}{d x}+u \frac{d u}{d x}\right)+$

$\left(\sum_{\text {gas }}^{K_{g}} h_{k} Y_{k}+\frac{u^{2}}{2}\right) a \sum_{\text {gas }}^{K_{g}} \dot{g}_{k} W_{k}=a\left(Q+\sum_{\text {gas }}^{K_{g}} \dot{g}_{k} W_{k} h_{k}\right)$

Momentum:

$A \frac{d p}{d x}+\rho u A \frac{d u}{d x}+\frac{a}{2} \rho u^{2} f+u a \sum_{g a s}^{K_{g}} \dot{g}_{k} W_{k}=0$

Site Fractions:

$\dot{s}_{k}=0$.

Here $x$ is the axial coordinate, $\rho$ the density of the gas mixture, $u$ the gas velocity, $A$ the crosssectional area, $a$ the surface area per unit length, 
$K_{g}$ the total number of gas phase species, $W_{k}$ the molecular weight of species $k, \dot{g}_{k}$ the molar production rate of species $k$ due to all surface reactions, $Y_{k}$ the mass fraction of species $k, \dot{\omega}_{k}$ the molar production rate of species $k$ due to gasphase reactions, $h_{k}$ the specific enthalpy of species $k, \bar{C}_{p}$ the mean heat capacity per unit mass of the gas, $T$ the gas temperature, $p$ the pressure, $f$ the friction factor, and $\dot{s}_{k}$ the net production rate of surface species $k$. The friction factor is a function of the local Reynolds number based on the tube diameter, $\mathrm{Re}_{\mathrm{D}}$. Specifically, for laminar flow $f=16 / \operatorname{Re}_{\mathrm{D}}$, while the Blasius formula is used for turbulent flow. In addition, although detailed thermodynamic properties are considered, for simplicity the mixture viscosity is assumed to be a power dependence on temperature [20] when calculating the local Reynolds number.

The underlying assumptions in the plug-flow model are that axial diffusion is negligible compared to axial convection and the radial transport times are much smaller than the axial convection time. As such, Raja et al. [18] suggested practical bounds on range over which the plug-flow approximation is valid, namely $\mathrm{D} / \mathrm{L}<<\operatorname{Re}_{\mathrm{D}} \mathrm{Sc}<<\mathrm{L} / \mathrm{D}$, where $\mathrm{Sc}$ is the Schmidt number. Based on this criterion, for the present microtube configuration, the plug-flow model would be valid for most experimental conditions with tube diameter being less than $0.8 \mathrm{~mm}$.

The gas-phase reaction mechanism was taken from Mueller et al. [8], involving eight gaseous species: $\mathrm{H}_{2}, \mathrm{O}_{2}, \mathrm{H}_{2} \mathrm{O}, \mathrm{O}, \mathrm{OH}, \mathrm{H}, \mathrm{HO}_{2}$, and $\mathrm{H}_{2} \mathrm{O}_{2}$. The surface reaction mechanism for $\mathrm{H}_{2} / \mathrm{O}_{2}$ mixtures on platinum was taken from Duetschmann et al. [21], including five surface species: $\mathrm{Pt}(\mathrm{s}), \mathrm{H}(\mathrm{s}), \mathrm{H}_{2} \mathrm{O}(\mathrm{s}), \mathrm{OH}(\mathrm{s})$, and $\mathrm{O}(\mathrm{s})$.

\section{Results and Discussion}

\section{Experimental}

Experimental results consist of a determination of the minimum catalyst preheat temperature for initiating/supporting combustion in the two submillimeter diameter tubes. Data are obtained with the tubes resistively heated by the power supply in voltage control mode and with reactive premixed gases passed through the tubes. Tube temperature and inlet pressure are monitored for an indication of exothermic reactions and composition changes in the gases.
Temperature data for the $0.8 \mathrm{~mm}$ I.D. palladium tube preheated to a peak temperature of $477 \mathrm{~K}$ and showing an exothermic reaction is given in fig. 6. The total mass flow is $0.00123 \mathrm{~g} / \mathrm{sec}$ of gaseous oxygen and gaseous hydrogen at an oxidizer to fuel mixture ratio of 0.8 (equivalence ratio 10.0). The thermocouples were located as shown in fig. 3 . The resistivity of palladium at these temperatures is $17.2 \times 10^{-8} \Omega-\mathrm{m}$ and the voltage drop across the tube is 1.21 Volts, giving an estimated power input of 15 Watts. At 10 seconds into the test TC1 has dropped to $338 \mathrm{~K}$, TC2 has dropped to $412 \mathrm{~K}$ as the gas picks up heat, but TC3 has risen to $511 \mathrm{~K}$ as the gases are heated by catalyzed reactions between TC 2 and TC 3 . At 10 seconds into the test TC3 starts a rapid rise to $750 \mathrm{~K}$. Heat from this reaction is conducted through the tube upstream toward TC2 which starts a rapid temperature rise to $815 \mathrm{~K}$ at 16 seconds into the test. Further conduction to the TC1 position is indicated by its rapid temperature rise at 40 seconds into the test. Steady state is reached at TC3 at approximately 60 seconds into the test. The test was terminated at 100 seconds, however, before steady state was reached at TC1.

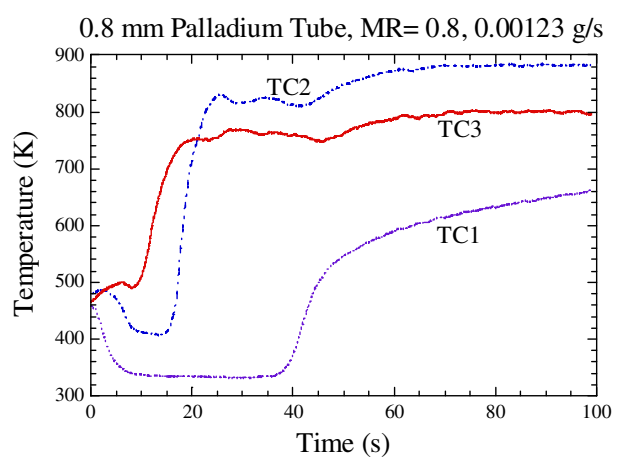

Figure 6. Temperature data for $0.8 \mathrm{~mm}$ I.D. palladium tube, $\mathrm{MR}=0.8,0.00123 \mathrm{~g} / \mathrm{sec}$.

The pressure in a plenum upstream of the tube is given in fig. 7. The pressure at the start of the test is $2.7 \mathrm{kPa}$ in the altitude test facility. The pressure rises rapidly to $34 \mathrm{kPa}$ at 3 seconds into the test and stays there until about 10 seconds into the test when catalyzed reactions start to drive the pressure up. The pressure then rises to $59 \mathrm{kPa}$ at 71 seconds into the test and stays there until the test is terminated at 100 seconds. This increase in the inlet pressure suggests that the flow is choked within the catalyst tube due to a rise in viscosity and friction factor as the gases are heated by the exothermic reaction. Subsequent plug-flow 
calculations also demonstrated that the gas flow in the microtube is choked when the imposed heat flux exceeds a critical value.

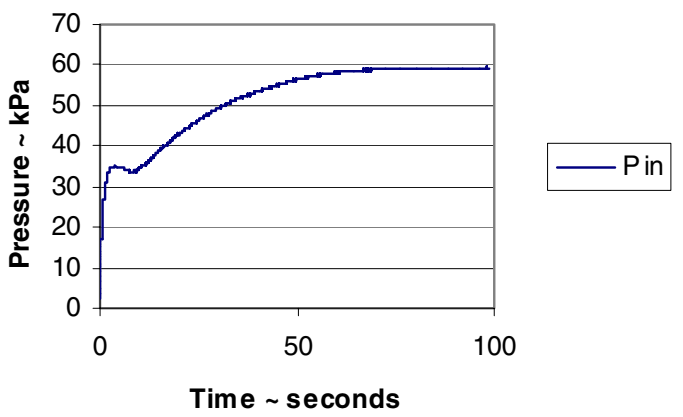

Figure 7. Pressure data for $0.8 \mathrm{~mm}$ I.D. palladium tube, $\mathrm{MR}=0.8,0.00123 \mathrm{~g} / \mathrm{sec}$.

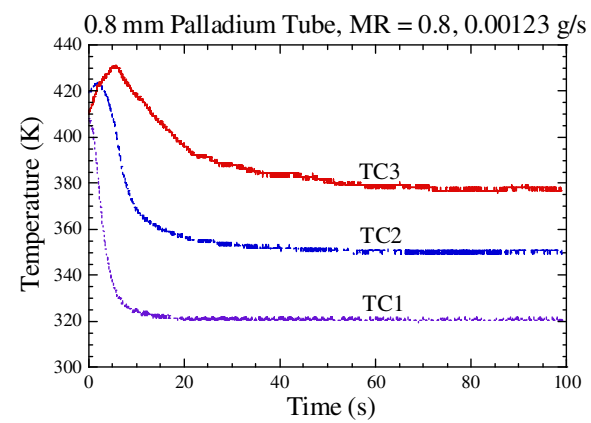

Figure 8. Non-ignition temperature data for $0.8 \mathrm{~mm}$ I.D. palladium tube, $\mathrm{MR}=0.8,0.00123 \mathrm{~g} / \mathrm{sec}$.

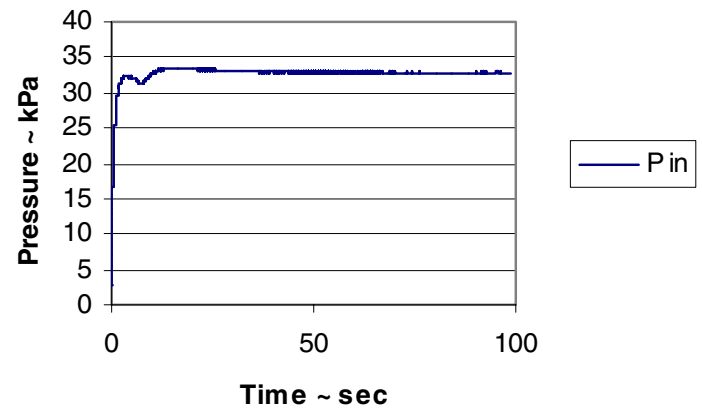

Figure 9. Non-ignition pressure data for $0.8 \mathrm{~mm}$ I.D. palladium tube, $\mathrm{MR}=0.8,0.00123 \mathrm{~g} / \mathrm{sec}$.

Temperature data for the $0.8 \mathrm{~mm}$ I.D. tube preheated to a peak temperature of $422 \mathrm{~K}$ and showing no reaction within the heated section are given in fig. 8. The total mass flow is $0.00123 \mathrm{~g} / \mathrm{sec}$ of gaseous oxygen and gaseous hydrogen at an oxidizer to fuel mixture ratio of 0.8 . Some reactions between TC2 and TC 3 cause the temperature of TC3 to rise to a peak of $430 \mathrm{~K}$ at 6 seconds into the test, otherwise all of the temperatures fall to a steady state profile of $\mathrm{TC} 1$ at $321 \mathrm{~K}, \mathrm{TC} 2$ at $351 \mathrm{~K}$, and TC3 at $377 \mathrm{~K}$. The corresponding pressure in a plenum upstream of the tube is given in fig. 9. The pressure rises rapidly and reaches a pressure of $33 \mathrm{kPa}$ at 15 seconds into the test.

Temperature data for the $0.8 \mathrm{~mm}$ I.D. tube preheated to a peak temperature of $589 \mathrm{~K}$ at a mixture ratio of 0.6 (equivalence ratio 13.3) and a mass flow of $0.00160 \mathrm{~g} / \mathrm{s}$ is given for a reacting case in fig. 10. The corresponding pressure data is given in fig. 11. This equivalence ratio is above the rich flammability limit predicted in fig. 2 . If the preheat temperature is reduced to approximately $530 \mathrm{~K}$, the temperature data shown in fig. 12 indicate that the reactions have not occurred within the heated section.

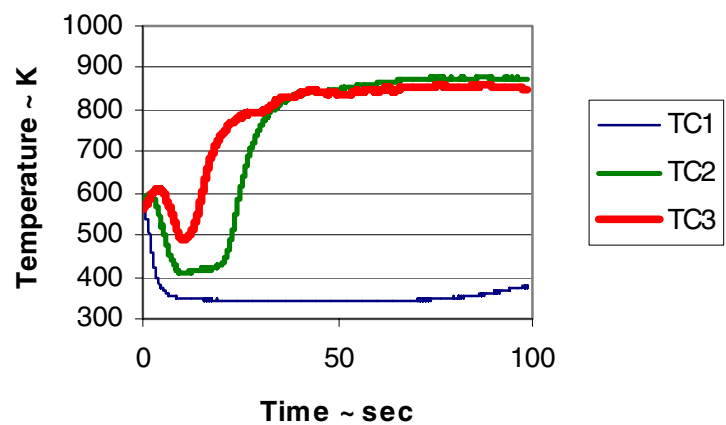

Figure 10. Temperature data for $0.8 \mathrm{~mm}$ I.D. palladium tube, $\mathrm{MR}=0.6,0.00160 \mathrm{~g} / \mathrm{sec}$.

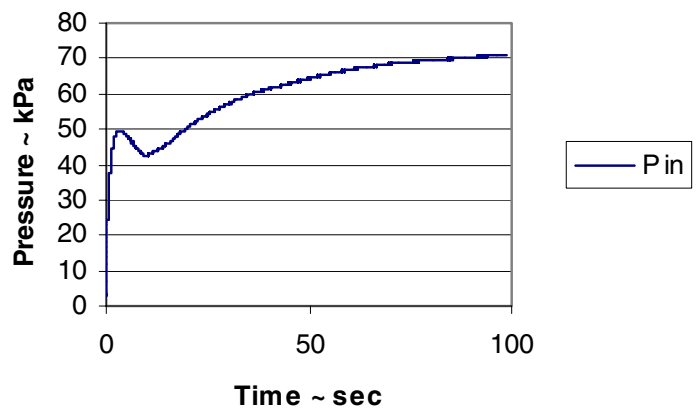

Figure 11. Pressure data for $0.8 \mathrm{~mm}$ I.D. palladium tube, $\mathrm{MR}=0.6,0.00160 \mathrm{~g} / \mathrm{sec}$.

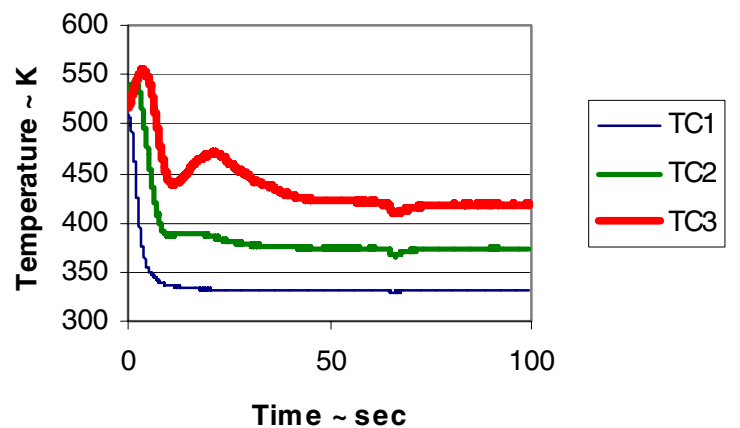

Figure 12. Non-ignition temperature data for $0.8 \mathrm{~mm}$ I.D. palladium tube, $\mathrm{MR}=0.6,0.00160 \mathrm{~g} / \mathrm{sec}$.

Temperature data for the $0.4 \mathrm{~mm}$ I.D. platinum tube preheated to a peak temperature of $640 \mathrm{~K}$ 
which shows an exothermic reaction is given in fig. 13. The total mass flow is $0.000412 \mathrm{~g} / \mathrm{sec}$ of gaseous oxygen and gaseous hydrogen at an oxidizer to fuel mixture ratio of 0.8 (equivalence ratio 10.0). The resistivity of platinum at these temperatures is $23.4 \times 10^{-8} \Omega-\mathrm{m}$ and the voltage drop across the tube is 1.41 Volts, giving an estimated power input of 31 Watts. At 30 seconds into the test, the thermocouples have dropped to their minimum values of TC1 at $400 \mathrm{~K}, \mathrm{TC} 2$ at $480 \mathrm{~K}$ and $\mathrm{TC} 3$ at $550 \mathrm{~K}$. The remaining 30 seconds of the test show an exothermic reaction taking place giving a rise in temperature at TC3 to $650 \mathrm{~K}$ at the end of the test. This test was terminated before steady state was reached. The pressure in a plenum upstream of the tube is given in fig. 14. The pressure rises to $43 \mathrm{kPa}$ at 30 seconds into the test and then rises to $48 \mathrm{kPa}$ at the end of the test, suggesting a choked flow due to a rise in viscosity and heat lease through the exothermic reaction.

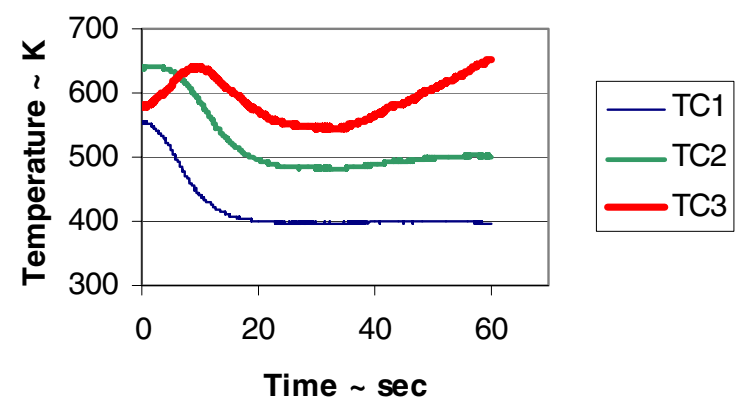

Figure 13. Temperature data for $0.4 \mathrm{~mm}$ I.D. platinum tube, $\mathrm{MR}=0.8,0.000412 \mathrm{~g} / \mathrm{sec}$.

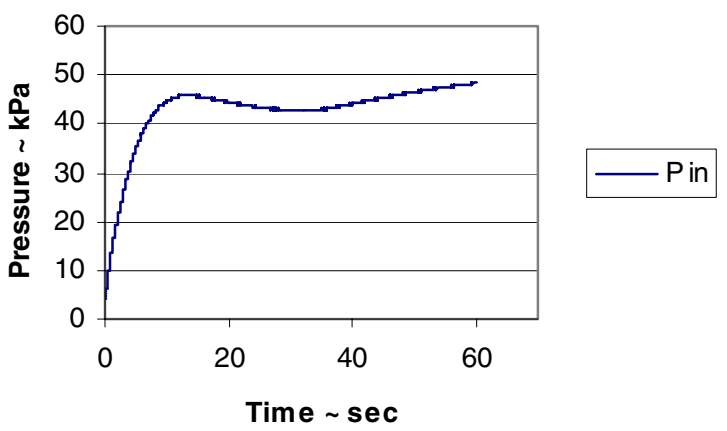

Figure 14. Pressure data for $0.4 \mathrm{~mm}$ I.D. platinum tube, $\mathrm{MR}=0.8,0.000412 \mathrm{~g} / \mathrm{sec}$.

Temperature data for the $0.4 \mathrm{~mm}$ I.D. tube preheated to a peak temperature of $585 \mathrm{~K}$ which shows only a very mild reaction are given in fig. 15. The total mass flow is $0.000412 \mathrm{~g} / \mathrm{sec}$ of gaseous oxygen and gaseous hydrogen at an oxidizer to fuel mixture ratio of 0.8 . Convection between TC2 and TC3 causes the temperature at TC3 to rise to a peak of $584 \mathrm{~K}$ at 10 seconds into the test, otherwise all of the temperatures fall to a steady state profile of TC1 at $380 \mathrm{~K}, \mathrm{TC} 2$ at $450 \mathrm{~K}$ and TC 3 at $501 \mathrm{~K}$ at 25 seconds into the test and remain these levels except for a slight rise in TC3 until the test is terminated at 69 seconds. The pressure in a plenum upstream of the tube is given in fig. 16 for this case. The pressure at the start of the test is $2.5 \mathrm{kPa}$ and rises rapidly to $43 \mathrm{kPa}$ at 30 seconds into the test as it did in the reacting case shown in fig. 14. The pressure then rises to a plateau of $47 \mathrm{kPa}$ at 65 seconds into the test indicating a mild viscosity change and remains there until the test is terminated at 69 seconds.

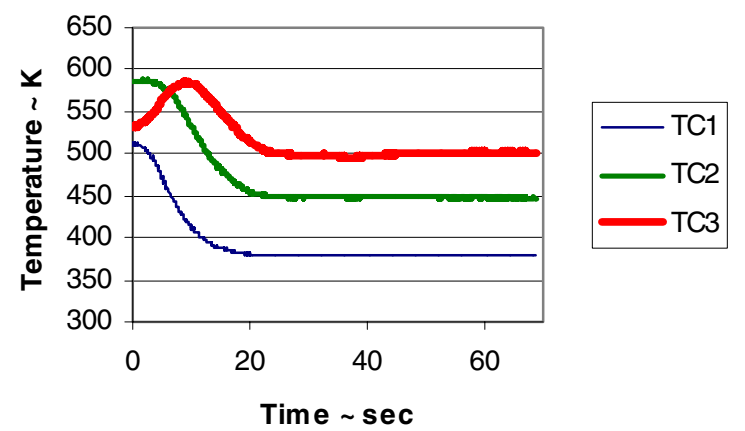

Figure 15. Non-ignition temperature data for $0.4 \mathrm{~mm}$ I.D. platinum tube, $\mathrm{MR}=0.8,0.000412 \mathrm{~g} / \mathrm{sec}$.

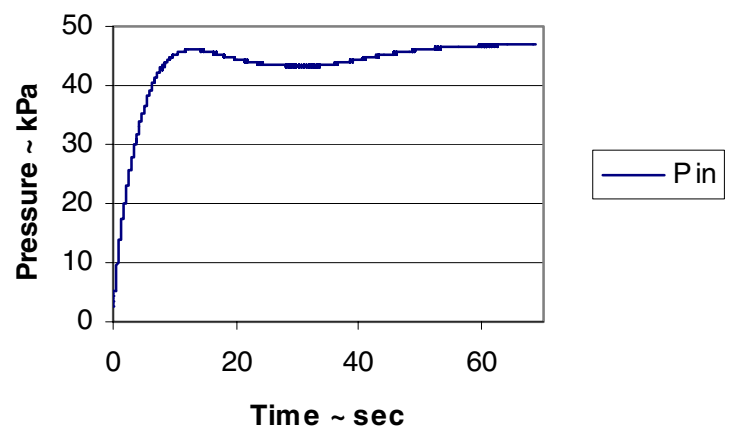

Figure 16. Non-ignition pressure data for $0.4 \mathrm{~mm}$ I.D. platinum tube, $\mathrm{MR}=0.8,0.000412 \mathrm{~g} / \mathrm{sec}$.

Temperature data for the $0.4 \mathrm{~mm}$ I.D. tube at a mixture ratio of 0.6 (equivalence ratio 13.3) and a mass flow of $0.000537 \mathrm{~g} / \mathrm{sec}$ is given for a reacting case in fig. 17. The peak preheat temperature of $640 \mathrm{~K}$ was used. Note that this equivalence ratio is above the rich flammability limit predicted in fig. 2. If the peak preheat temperature is reduced to $585 \mathrm{~K}$, the temperature data shown in fig. 18 indicate that less reactions have occurred. 


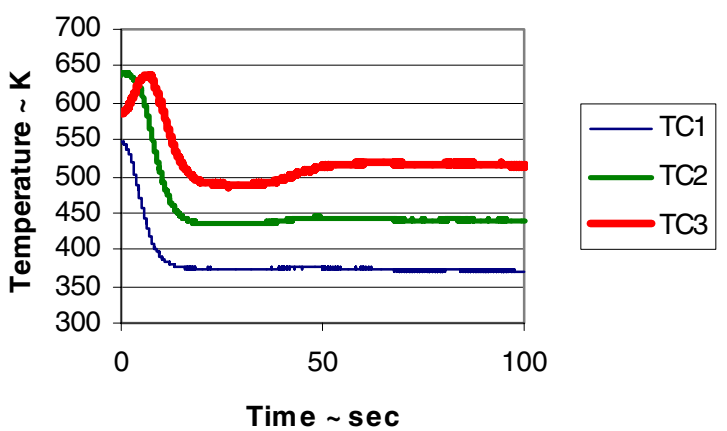

Figure 17. Temperature data for $0.4 \mathrm{~mm}$ I.D. platinum tube, $\mathrm{MR}=0.6,0.000537 \mathrm{~g} / \mathrm{sec}$.

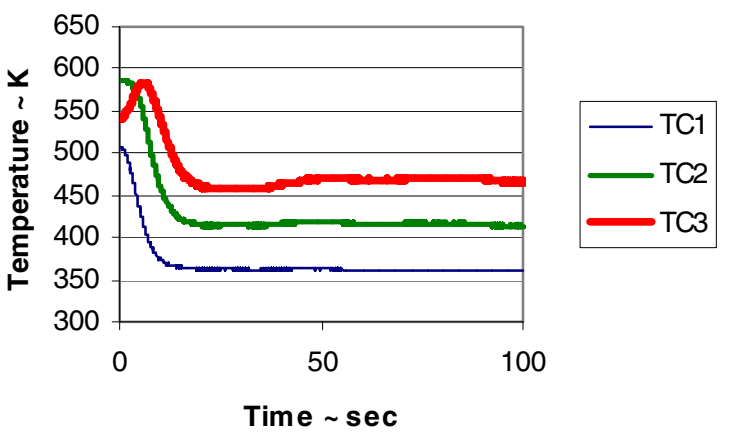

Figure 18. Temperature data for $0.4 \mathrm{~mm}$ I.D. platinum tube, $\mathrm{MR}=0.6,0.000537 \mathrm{~g} / \mathrm{sec}$.

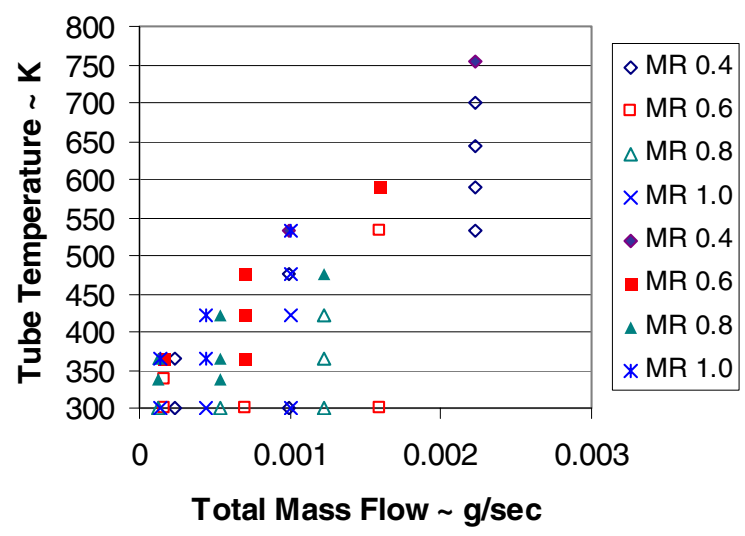

Figure 19. Ignition data for $0.8 \mathrm{~mm}$ I.D. palladium tube. Open symbols are non-ignition within the heated section and solid symbols are ignition as indicated by tube temperature rise.

These data and data at other mass flows and fuel rich mixture ratios are shown on mass flow versus preheat temperature plots in fig. 19 for the $0.8 \mathrm{~mm}$ I.D. palladium tube and fig. 20 for the $0.4 \mathrm{~mm}$ platinum tube. Using temperature and pressure rise as an indication of reactions the solid symbols indicate those test conditions where reactions within the heated section were observed. As mass flow decreases the preheat temperature required to initiate reactions decreases. For the $0.8 \mathrm{~mm}$ palladium tube the lowest preheat temperature for reactions was $340 \mathrm{~K}$ at a mixture ratio of 0.8 and a mass flow of $0.000128 \mathrm{~g} / \mathrm{sec}$. Above a mass flow of $0.0022 \mathrm{~g} / \mathrm{sec}$ reactions did not occur at any preheat temperature in the $0.8 \mathrm{~mm}$ I.D. palladium tube, $190 \mathrm{~mm}$ long with $160 \mathrm{~mm}$ resistively heated.

For the $0.4 \mathrm{~mm}$ I.D. platinum tube, the lowest preheat temperature for reactions was $480 \mathrm{~K}$ at a mixture ratio of 1.0 and a mass flow of $0.000187 \mathrm{~g} / \mathrm{sec}$. Above a mass flow of $0.00054 \mathrm{~g} / \mathrm{sec}$ reactions did not occur at any preheat temperature in the $0.4 \mathrm{~mm}$ I.D. platinum tube, $100 \mathrm{~mm}$ long with $70 \mathrm{~mm}$ resistively heated.

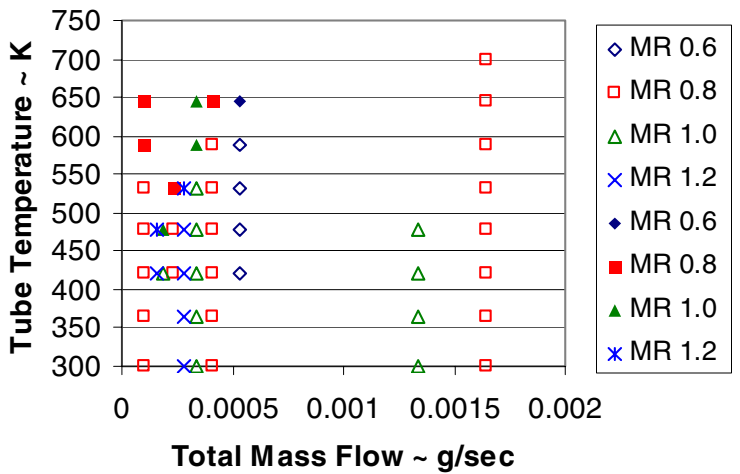

Figure 20. Ignition data for $0.4 \mathrm{~mm}$ I.D. platinum tube. Open symbols are non-ignition within the heated section and solid symbols are ignition as indicated by tube temperature rise.

\section{Computational}

While a detailed transient simulation on microtube experiments will be carried out in the future, as a first step the present steady-state plugflow model would provide insights into the critical conditions leading to catalytic ignition as well as the axial variations of gas temperature, flow velocity, gas pressure, gas-phase composition, and site fraction of surface species. Platinum tube is first studied. The inlet mixture temperature and the oxidizer to fuel mixture ratio are kept constant at $300 \mathrm{~K}$ and 1.0 , respectively. For this rich $\mathrm{H}_{2} / \mathrm{O}_{2}$ mixture, the inlet viscosity is 0.12 millipoise. Moreover, as demonstrated in fig. 1, the diameters of the platinum microtubes studied herein are smaller than the characteristic flame thickness. In the following, effects of imposed heat flux (Q), inlet velocity (U), and microtube diameter on catalytic ignition are systematically examined.

\section{Effect of Input Heat Flux}

Consider a platinum tube of $\mathrm{D}=0.4 \mathrm{~mm}$, $\mathrm{L}=100 \mathrm{~mm}$, and $\ell_{1}=\ell_{2}=15 \mathrm{~mm}$. With inlet 
pressure of $0.5 \mathrm{~atm}$ and inlet velocity of $50 \mathrm{~m} / \mathrm{s}$, the inlet Reynolds number is 128 . Figure 21 plots the axial variations of gas temperature and pressure from the inlet with various input heat fluxes. The microtube is heated within the range bounded by two long dashed lines. It is seen that with $\mathrm{Q}=0.5$ $\mathrm{W} / \mathrm{cm}^{2}$, catalytic ignition cannot be achieved for the given tube length. With increasing $\mathrm{Q}$ to 0.55 $\mathrm{W} / \mathrm{cm}^{2}$, ignition occurs near the exit of microtube and outside the heated section. Note that experimentally tube temperatures were monitored for an indication of catalytic ignition. Since thermocouples were spot welded within the heated section, computed results of fig. 21 imply that the experimentally-determined critical heat flux leading to ignition may be overestimated. Therefore, measurements of exit temperature and composition are needed for accurate determination of the ignition condition.

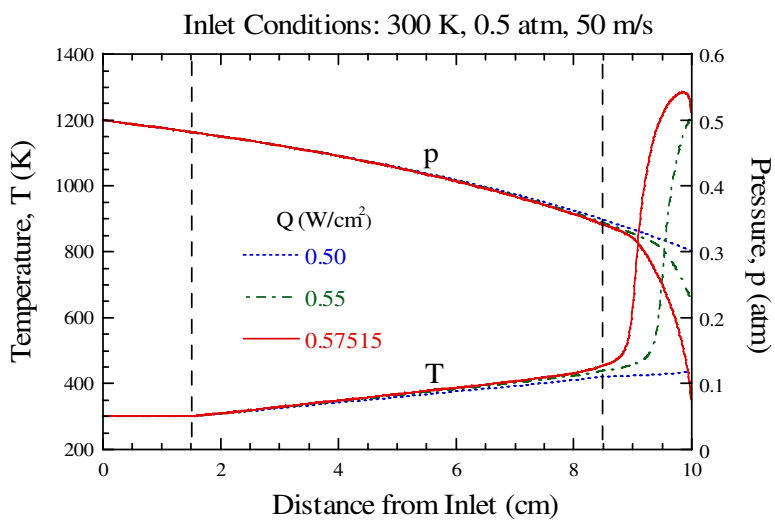

Figure 21. Axial profiles of temperature and pressure in a $0.4 \mathrm{~mm}$ I.D platinum tube with various input heat fluxes. Inlet conditions: $\mathrm{MR}=1.0,300 \mathrm{~K}, \mathrm{p}=0.5 \mathrm{~atm}$, and $\mathrm{U}=50 \mathrm{~m} / \mathrm{s}$. The section bounded by two long-dashed lines is heated with uniform heat flux.

Figure 22 demonstrates the variations of Mach number corresponding to fig. 21. For a given heat input, Mach number increases towards the tube exit, while pressure decreases as the flow accelerates. Figure 22 also shows that further increasing the imposed heat flux beyond $0.57515 \mathrm{~W} / \mathrm{cm}^{2}$, the flow is choked somewhere in the tube. Once the flow is choked, the steady state solutions fail to exist for the given inlet conditions.

For $\mathrm{Q}=0.57515 \mathrm{~W} / \mathrm{cm}^{2}$, fig. 23 further plots the spatially-resolved profiles of the mole fractions of gas species, including $\mathrm{H}_{2}, \mathrm{O}_{2}$, and $\mathrm{H}_{2} \mathrm{O}$, as well as the surface site fractions of $\mathrm{Pt}(\mathrm{s})$ and $\mathrm{H}(\mathrm{s})$. It is seen that for the present fuel rich condition the surface is almost covered entirely by $\mathrm{H}(\mathrm{s})$ prior to the initiation of significant exothermic reactions. With increasing temperature, the surface coverage of $\mathrm{Pt}(\mathrm{s})$ increases and eventually dominates, leading to the consumptions of $\mathrm{H}_{2}$ and $\mathrm{O}_{2}$ and the production of $\mathrm{H}_{2} \mathrm{O}$.

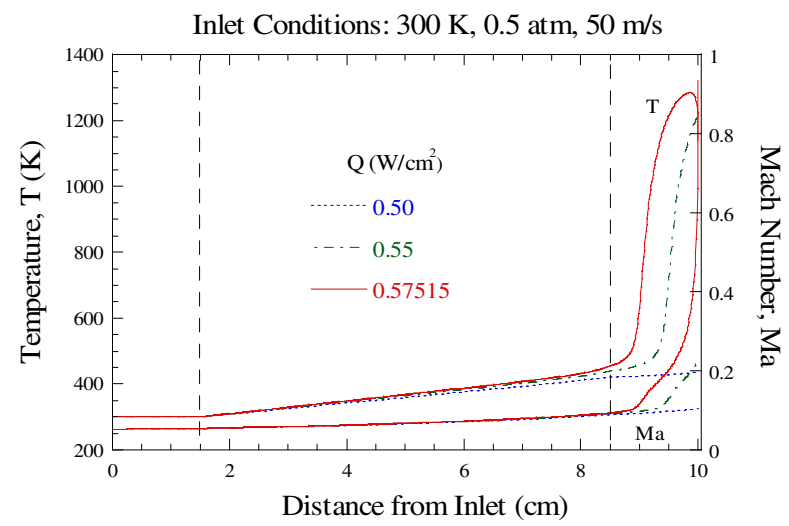

Figure 22. Axial profiles of temperature and Mach number in a $0.4 \mathrm{~mm}$ I.D platinum tube with various input heat fluxes. Inlet conditions: $M R=1.0,300 \mathrm{~K}, \mathrm{p}=0.5 \mathrm{~atm}$, and $\mathrm{U}=50 \mathrm{~m} / \mathrm{s}$. The section bounded by two long-dashed lines is heated with uniform heat flux.

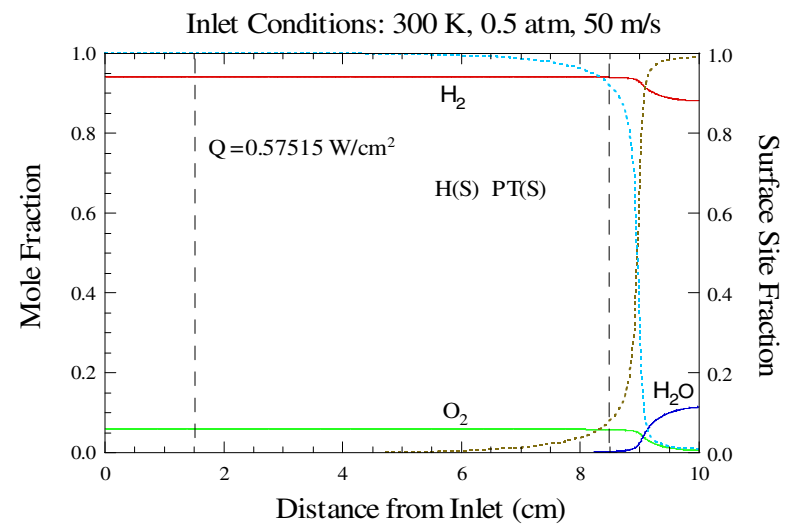

Figure 23. Axial profiles of gaseous species mole fractions and surface coverage in a $0.4 \mathrm{~mm}$ I.D platinum tube with an input heat flux of $0.57515 \mathrm{~W} / \mathrm{cm}^{2}$. Inlet conditions: $\mathrm{MR}=1.0$, $300 \mathrm{~K}, \mathrm{p}=0.5 \mathrm{~atm}$, and $\mathrm{U}=50 \mathrm{~m} / \mathrm{s}$. The section bounded by two long-dashed lines is heated with uniform heat flux.

\section{Effect of Inlet Velocity}

For a given heat input of $0.15 \mathrm{~W} / \mathrm{cm}^{2}$ in a platinum tube of $\mathrm{D}=0.4 \mathrm{~mm}, \mathrm{~L}=100 \mathrm{~mm}$, and $\ell_{1}=\ell_{2}=15 \mathrm{~mm}$, figs. 24 and 25 compare the axial distributions of temperature, pressure, and Mach number at three different inlet velocities, namely $\mathrm{U}=10,20$, and $25 \mathrm{~m} / \mathrm{s}$. The corresponding inlet Reynolds numbers are 17.4, 34.8, and 43.5, respectively. The inlet pressure is $0.34 \mathrm{~atm}$. As expected, lower inlet velocity facilitates ignition due to longer residence time. It is also evident that the flow is accelerated both frictionally and thermally (if with significant heat release). 


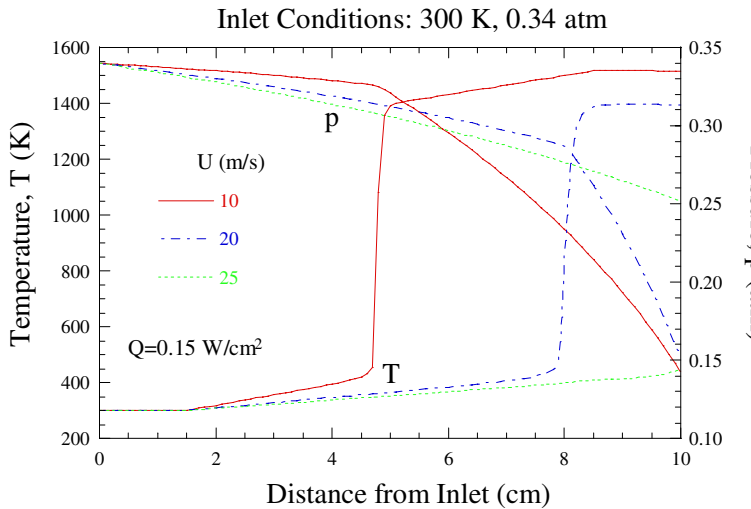

Figure 24. Comparison of axial profiles of temperature and pressure in a $0.4 \mathrm{~mm}$ I.D platinum tube with various inlet velocities. The input heat flux is $0.15 \mathrm{~W} / \mathrm{cm}^{2}$. Inlet conditions: $\mathrm{MR}=1.0,300 \mathrm{~K}, \mathrm{p}=0.34 \mathrm{~atm}$.

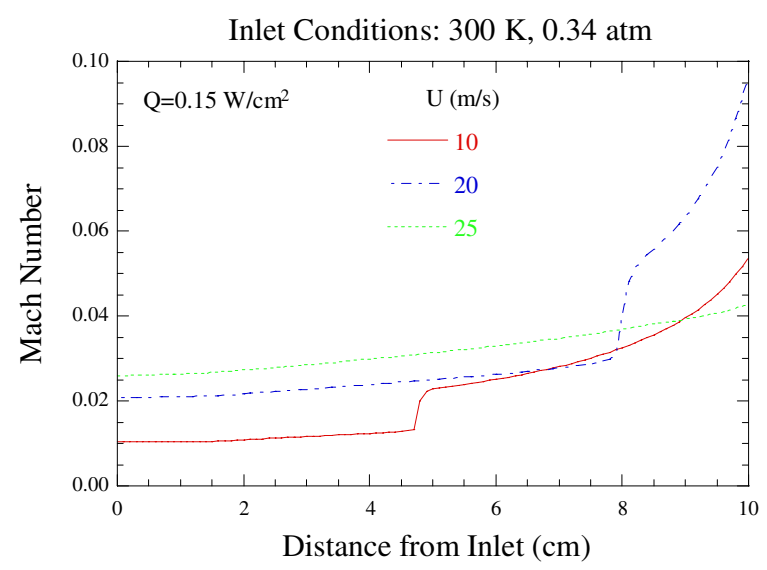

Figure 25. Comparison of axial profiles of Mach number in a $0.4 \mathrm{~mm}$ I.D platinum tube with various inlet velocities. The input heat flux is $0.15 \mathrm{~W} / \mathrm{cm}^{2}$. Inlet conditions: $\mathrm{MR}=1.0,300$ $\mathrm{K}, \mathrm{p}=0.34 \mathrm{~atm}$.

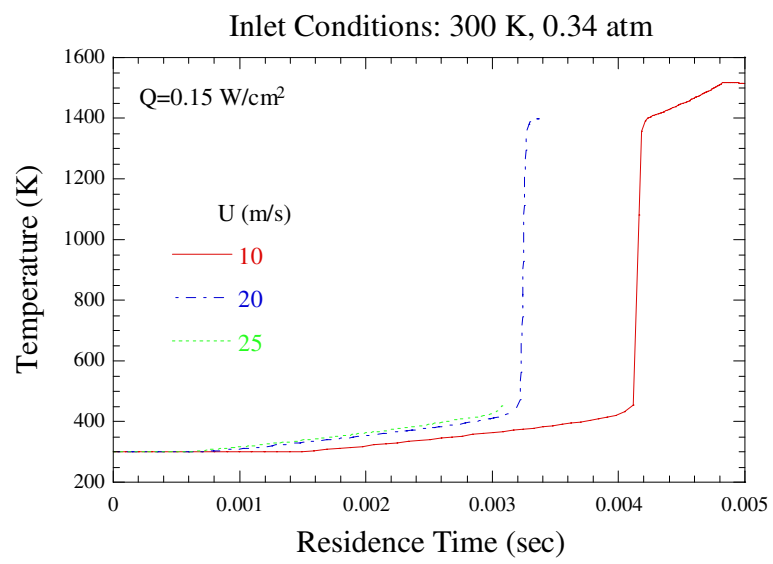

Figure 26. Comparison of temperature evolutions as a function of residence time in a $0.4 \mathrm{~mm}$ I.D platinum tube with various inlet velocities. The input heat flux is $0.15 \mathrm{~W} / \mathrm{cm}^{2}$. Inlet conditions: $\mathrm{MR}=1.0,300 \mathrm{~K}$, and $\mathrm{p}=0.34 \mathrm{~atm}$.
Figure 26 further re-plots the temperature distributions of fig. 24 in terms of residence time. It is seen that catalytic ignition is possible when the local temperature is heated up to exceed a critical value. For the present condition, this critical temperature is found to be around $460 \mathrm{~K}$, which is very close to the lowest preheat temperature, $480 \mathrm{~K}$, found in the sub-atmospheric experiments.

\section{Effect of Gas-Phase Reactions}

For most of the conditions investigated herein, either the microtube diameter is smaller than the characteristic flame thickness of the premixture or the mixture composition is beyond the flammability limit. As such, it is not expected that gas-phase reactions account for the major heat release. To demonstrate the insignificance of the gas-phase reactions, computed results were compared with and without gas-phase reactions. Figure 27 compares a case with a platinum tube of $\mathrm{D}=0.4 \mathrm{~mm}, \mathrm{~L}=100 \mathrm{~mm}, \ell_{1}=\ell_{2}=15 \mathrm{~mm}$, and $\mathrm{Q}=2 \mathrm{~W} / \mathrm{cm}^{2}$. Inlet pressure and velocity are respectively atmospheric pressure and $20 \mathrm{~m} / \mathrm{s}$. In fig. 27, lines are the computed results obtained with both gas-phase and surface reactions, while symbols denote the solutions considering surface reactions only. For clarity, the symbols do not represent the actual grid distribution employed in the calculations. The closeness of the two sets of numerical data, including axial profiles of temperature and major species, indicates that for microtube modeling gas-phase reactions can be neglected.

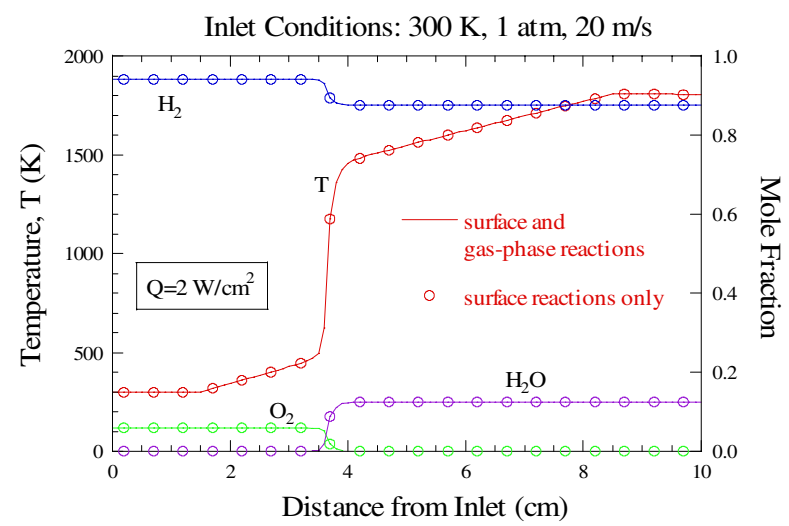

Figure 27. Axial profiles of temperature and major gaseous species in a $0.4 \mathrm{~mm}$ I.D platinum tube with an input heat flux of $2 \mathrm{~W} / \mathrm{cm}^{2}$. Inlet conditions: $\mathrm{MR}=1.0,300 \mathrm{~K}, \mathrm{p}=1 \mathrm{~atm}$, and $\mathrm{U}=20 \mathrm{~m} / \mathrm{s}$. The symbols do not represent the actual grid distribution employed in the calculation. 


\section{Effect of Microtube Diameter}

We have demonstrated the importance of residence time leading to ignition. For a given global residence time, it is also of interest to compare the critical heat flux for initiating ignition with various diameters of microtube. In the following calculations, the inlet conditions are $\mathrm{MR}=1.0,300 \mathrm{~K}$, and $\mathrm{p}=0.6 \mathrm{~atm}$. The global residence time, representing by $\mathrm{L} / \mathrm{U}$, and the tube length to diameter ratio, $\mathrm{L} / \mathrm{D}$, are fixed at $1 / 300$ and 250, respectively. Moreover, for all cases $\ell_{1}=$ $\ell_{2}=\ell$ and $\ell / \mathrm{L}=0.15$. Three tube diameters were compared, including $\mathrm{D}=0.8,0.4$, and $0.1 \mathrm{~mm}$. As a result, the corresponding inlet Reynolds numbers are 368,92 , and 5.76 .

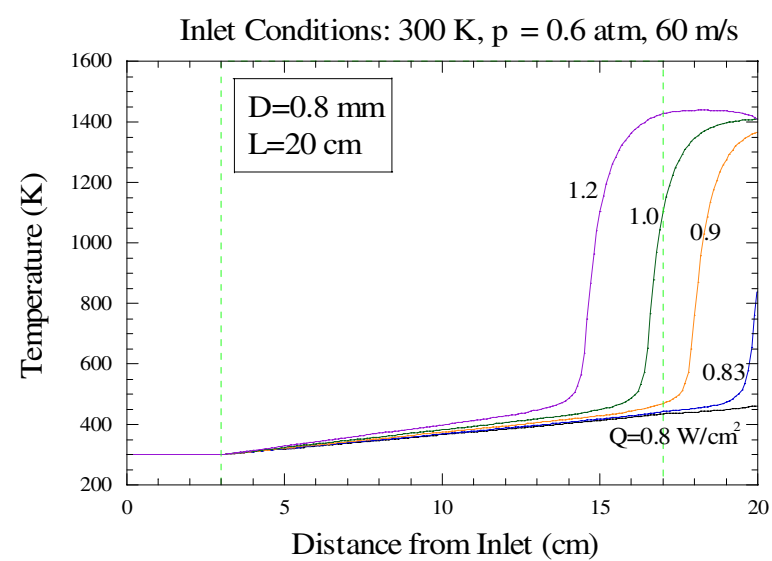

Figure 28. Comparison of axial profiles of gas temperature in a $0.8 \mathrm{~mm}$ I.D platinum tube with various heat fluxes. $\mathrm{L} / \mathrm{D}=250$ and inlet conditions are $\mathrm{MR}=1.0,300 \mathrm{~K}, \mathrm{p}=0.6$ atm, and $U=60 \mathrm{~m} / \mathrm{s}$. The section bounded by two longdashed lines is heated with uniform heat flux.

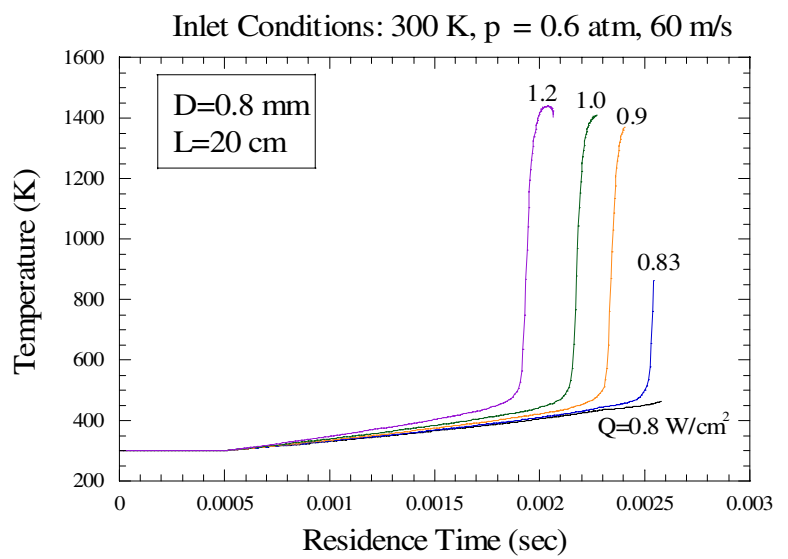

Figure 29. Comparison of temperature evolutions as a function of residence time for fig. 28 .

Figures 28-33 plots the temperature profiles in terms of both axial coordinate and residence time. For each microtube, axial distributions of gas temperature were compared with various input heat fluxes. The critical heat fluxes resulting in ignition for $\mathrm{D}=0.8,0.4$, and $0.1 \mathrm{~mm}$ are found to be around $0.83,0.38$, and $0.0795 \mathrm{~W} / \mathrm{cm}^{2}$, respectively. Thus, the smaller the tube, the less the critical heat flux required. In addition, the critical heat flux is roughly proportional to the tube diameter. This can be explained based on the surface area to volume ratio, which varies inversely with tube diameter. As the preceding discussion of the physical processes and scaling of catalytic combustion systems, heterogeneous catalysis is favored as a result of increased surface-to-volume ratio.

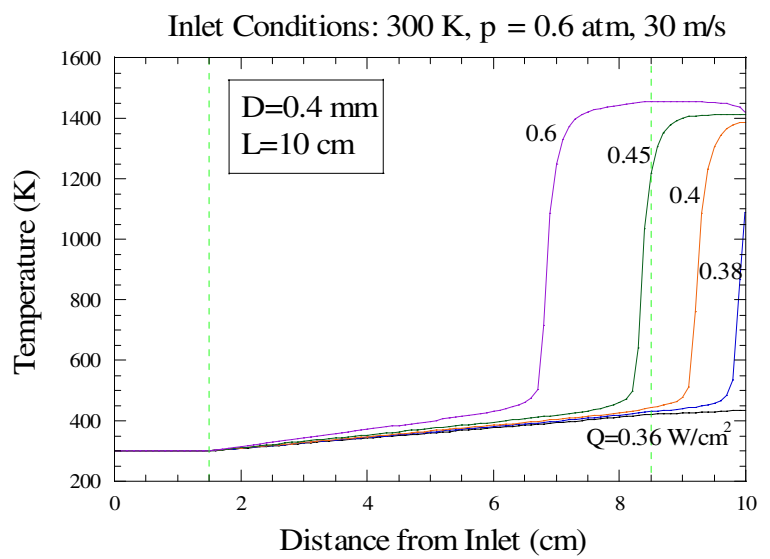

Figure 30. Comparison of axial profiles of gas temperature in a $0.4 \mathrm{~mm}$ I.D platinum tube with various heat fluxes. $\mathrm{L} / \mathrm{D}=250$ and inlet conditions: $\mathrm{MR}=1.0,300 \mathrm{~K}, \mathrm{p}=0.6 \mathrm{~atm}$, and $U=30 \mathrm{~m} / \mathrm{s}$. The section bounded by two long-dashed lines is heated with uniform heat flux.

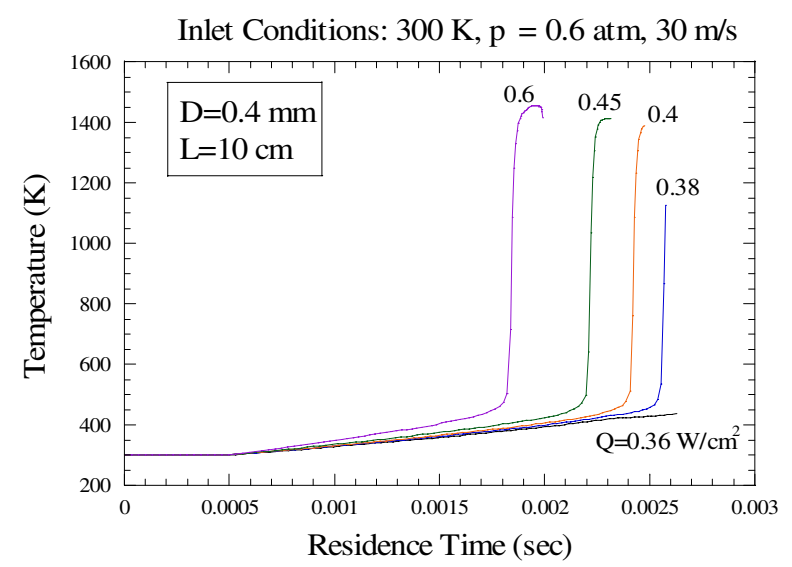

Figure 31. Comparison of temperature evolutions as a function of residence time for fig. 30 . 


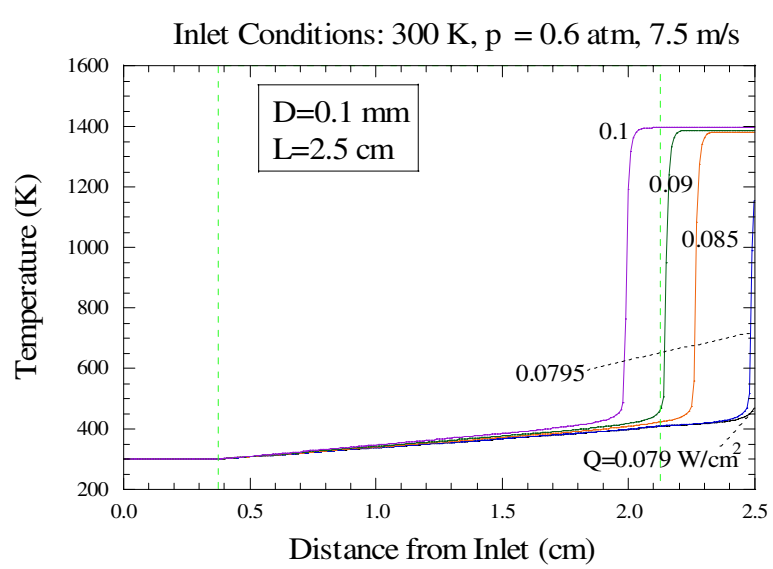

Figure 32. Comparison of axial profiles of gas temperature in a $0.1 \mathrm{~mm}$ I.D platinum tube with various heat fluxes. $\mathrm{L} / \mathrm{D}=250$ and inlet conditions: $\mathrm{MR}=1.0,300 \mathrm{~K}, \mathrm{p}=0.6 \mathrm{~atm}$, and $U=7.5 \mathrm{~m} / \mathrm{s}$. The section bounded by two long-dashed lines is heated with uniform heat flux.

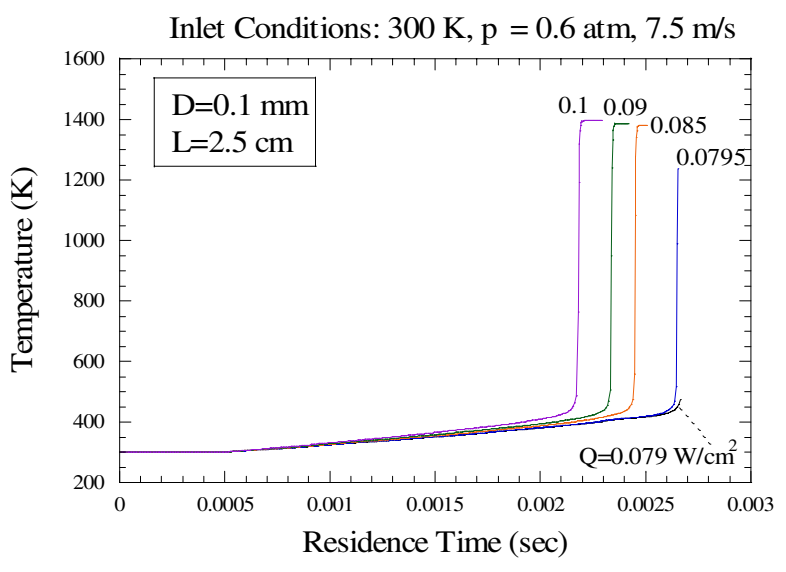

Figure 33. Comparison of temperature evolutions as a function of residence time for fig. 32 .

\section{Summary}

New micro-spacecraft will require new micropropulsion technology, which will require the development of micro-combustors. The heat release rate in the combustor scales with volume, while heat loss rate scales with surface area. Consequently, heat loss eventually dominates over heat release when the combustor size becomes smaller, thereby leading to flame quenching. The limitations imposed on chamber length and diameter has an immediate impact on the degree of miniaturization of a micro-combustor. One viable combustion alternative is to take advantage of surface catalysis. The favorable effects of surface catalysis associated with the high surfaceto-volume ratio as the combustor size is reduced can offset the wall quenching effects. Flame thickness and reaction zone thickness calculations predict that the diameters of our test apparatus are below the quenching diameter of the gaseous oxygen and gaseous hydrogen propellants in subatmospheric tests.

Miniature flame tube apparatus is chosen for study because micro-tubes can be easily fabricated from known catalyst materials and their simplicity in geometry can be used in fundamental simulations to more carefully characterize the measured heat transfer and pressure losses for validation purposes. Data on the temperature and pressure rise as a function of time in resistively heated platinum and palladium microtubes were used as an indication of exothermic reactions in a series of tests varying mass flow, preheat temperature, and fuel rich mixture ratio. As mass flow decreases the preheat temperature required to initiate reactions is shown to decrease.

For the $0.8 \mathrm{~mm}$ palladium tube, $190 \mathrm{~mm}$ long with $160 \mathrm{~mm}$ resistively heated, the lowest preheat temperature for reactions was $340 \mathrm{~K}$ at a mixture ratio of 0.8 and a mass flow of $0.000128 \mathrm{~g} / \mathrm{sec}$. Above a mass flow of $0.0022 \mathrm{~g} / \mathrm{sec}$ reactions did not occur at any preheat temperature in the $0.8 \mathrm{~mm}$ I.D. palladium tube. For the $0.4 \mathrm{~mm}$ I.D. platinum tube, $100 \mathrm{~mm}$ long with $70 \mathrm{~mm}$ resistively heated, the lowest preheat temperature for reactions was $480 \mathrm{~K}$ at a mixture ratio of 1.0 and a mass flow of $0.000187 \mathrm{~g} / \mathrm{sec}$. Above a mass flow of $0.00054 \mathrm{~g} / \mathrm{sec}$ reactions did not occur at any preheat temperature in the $0.4 \mathrm{~mm}$ I.D. platinum tube.

A plug flow model with detailed gas-phase and surface chemistry was used to provide insights into the present microtube experiments. Computed results for the $\mathrm{H}_{2} / \mathrm{O}_{2}$ mixtures reacting on platinum show that there exists a critical heat flux input for critical ignition. Further increasing the imposed heat flux, the flow can be choked within the tube. The minimally required temperature leading to ignition agrees quite well with the observed value. Simulations also suggest the need for measurements of the exit temperature and composition for accurate determination of the ignition condition. 


\section{References}

1. Schneider, S.J., Boyarko, G.A., and Sung, C.J., "Catalyzed Ignition of Bipropellants in Microtubes," AIAA 2003-0764, 2003.

2. Mueller, J., "Thruster Options for Microspacecraft: A Review and Evaluation of Existing Hardware and Emerging Technologies," AIAA 97-3058, 1997.

3. Fernandez-Pello, A.C., "Micropower Generation Using Combustion: Issues and Approaches," Proceedings of the Combustion Institute, Volume 29, pp. 883-899, 2002.

4. London, A.P., Epstein, A.H., and Kerrebrock, J.L., "High-Pressure Bipropellant Microrocket Engine," Journal of Propulsion and Power, Volume 17, No. 4, pp. 780-787, 2001.

5. Williams, F.A., Combustion Theory, $2^{\text {nd }}$ Edition, Addison-Wesley Publishing Company, Menlo Park, California, 1985.

6. Glassman, I., Combustion, $3^{\text {rd }}$ Edition, Academic Press, San Diego, CA, 1997.

7. Kee, R.J., Grcar, J.F., Smooke, M.D., and Miller, J.A., "A Fortran Program for Modeling Steady Laminar One-Dimensional Premixed Flames," Sandia Report SAND858240, 1985.

8. Mueller, M.A., Yetter, R.A., and Dryer, F.L., "Flow Reactor Studies and Kinetic Modeling of the $\mathrm{H}_{2} / \mathrm{O}_{2} / \mathrm{NO}_{\mathrm{x}}$ and $\mathrm{CO} / \mathrm{H}_{2} \mathrm{O} / \mathrm{O}_{2} / \mathrm{NO}_{\mathrm{x}}$ Reactions," International Journal of Chemical Kinetics 31, pp. 705-724 (1999).

9. Nishioka, M., Law, C.K., and Takeno, T., "A Flame-Controlling Continuation Method for Generating S-Curve Responses with Detailed Chemistry," Combustion and Flame 104, pp. 328-342, 1996.

10. Soufiani, A., and Taine, J., "High Temperature Gas Radiative Property Parameters of Statistical Narrowband Model for $\mathrm{H}_{2} \mathrm{O}, \mathrm{CO}_{2}$, and $\mathrm{CO}$ and Correlated $\mathrm{k}$ Model for $\mathrm{H}_{2} \mathrm{O}$ and $\mathrm{CO}_{2}$," International Journal of Heat Mass Transfer 40, pp. 987991, 1997.

11. He, L. and Clavin, P., "Premixed HydrogenOxygen Flames. Part II: Quasi-isobaric Ignition Near the Flammability Limits," Combustion and Flame 93, pp. 408-420, 1993.

12. Christiansen, E.W., Sung, C.J., and Law, C.K., "Pulsating Instability in the Fundamental Flammability Limit of Rich
Hydrogen/Air Flames," Proceedings of the Combustion Institute 27, pp. 555-562, 1998.

13. Christiansen, E.W., Law, C.K., and Sung, C.J., "Steady and Pulsating Propagation and Extinction of Rich Hydrogen/Air Flames at Elevated Pressures," Combustion and Flame 124, pp. 35-49, 2001

14. Groppo, G., Tronconi, E., and Forzatti, P., "Modeling of Catalytic Combustors for Gas Turbine Applications," Catalysis Today 17: 237-250 (1993).

15. Waitz, I.A., Gauba, G., and Tzeng, Y.S., "Combustors for Micro-Gas Turbine Engines," Journal of Fluids Engineering 120: 109-117 (1998).

16. Maruta, K., Takeda, K., Jeongmin A., Borer K., Sitzki, L., Ronney, P.D., Deutschmann, O., "Extinction Limits of Catalytic Combustion in Microchannels," Proceedings of the Combustion Institute, Volume 29, pp. 957-963, 2002.

17. Larson, R.S., "Plug: a Fortran Program for the Analysis of Plug Flow reactors with GasPhase and Surface Chemistry," Sandia Report SAND96-8211, Sandia National Laboratories, New Mexico, 1996.

18. Raja, L.L., Kee, R.J., Deutschmann, O., Warnatz, J., and Schmidt, L.D., "A Critical Evaluation of Navier-Stokes, BoundaryLayer, and Plug-Flow Models of the Flow and Chemistry in a Catalytic-Combustion Monolith," Catalysis Today, Volume 59, pp. 47-60, 2000.

19. deGroot, W.A. et al., "Electrolysis Propulsion for Spacecraft Applications," AIAA 97-2948, 1997.

20. Smooke, M.D. and Giovangigli, V., "Formulation of the Premixed and Nonpremixed Test Problem," Lecture Notes in Physics, Series 384, Chapter 1, Spring-Verlag, New York, 1991.

21. Deutschmann, O., Schmidt, R., Behrendt, F., and Warnatz, J., "Numerical Modeling of Catalytic Ignition," Proceedings of the Combustion Institute, Volume 26, pp. 17471754, 1996. 
Public reporting burden for this collection of information is estimated to average 1 hour per response, including the time for reviewing instructions, searching existing data sources, gathering and maintaining the data needed, and completing and reviewing the collection of information. Send comments regarding this burden estimate or any other aspect of this collection of information, including suggestions for reducing this burden, to Washington Headquarters Services, Directorate for Information Operations and Reports, 1215 Jefferson Davis Highway, Suite 1204, Arlington, VA 22202-4302, and to the Office of Management and Budget, Paperwork Reduction Project (0704-0188), Washington, DC 20503.

\begin{tabular}{|l|l|l|}
\hline 1. AGENCY USE ONLY (Leave blank) & $\begin{array}{c}\text { 2. REPORT DATE } \\
\text { October } 2003\end{array}$ & $\begin{array}{r}\text { 3. REPORT TYPE AND DATES COVERED } \\
\text { Technical Memorandum }\end{array}$ \\
\hline
\end{tabular}

\section{TITLE AND SUBTITLE}

Catalyzed Combustion of Bipropellants for Micro-Spacecraft Propulsion

\section{FUNDING NUMBERS}

WBS-22-755-04-08

\section{AUTHOR(S)}

Steven J. Schneider, Chih-Jen Sung, and George A. Boyarko

\section{PERFORMING ORGANIZATION NAME(S) AND ADDRESS(ES)}

National Aeronautics and Space Administration

John H. Glenn Research Center at Lewis Field

Cleveland, Ohio 44135-3191

8. PERFORMING ORGANIZATION REPORT NUMBER

\section{E-14171}

\section{SPONSORING/MONITORING AGENCY NAME(S) AND ADDRESS(ES)}

National Aeronautics and Space Administration

Washington, DC 20546-0001

10. SPONSORING/MONITORING AGENCY REPORT NUMBER

NASA TM-2003-212613

AIAA-2003-4924

\section{SUPPLEMENTARY NOTES}

Prepared for the 39th Joint Propulsion Conference and Exhibit cosponsored by the AIAA, ASME, SAE, and ASEE, Huntsville, Alabama, July 20-23, 2003. Steven J. Schneider, NASA Glenn Research Center; and Chih-Jen Sung and George A. Boyarko, Case Western Reserve University, Cleveland, Ohio 44106. Responsible person,

Steven J. Schneider, organization code 5430, 216-977-7484.

12a. DISTRIBUTION/AVAILABILITY STATEMENT

12b. DISTRIBUTION CODE

Unclassified - Unlimited

Subject Category: 20

Distribution: Nonstandard

Available electronically at http://gltrs.grc.nasa.gov

This publication is available from the NASA Center for AeroSpace Information, 301-621-0390.

\section{ABSTRACT (Maximum 200 words)}

This paper addresses the need to understand the physics and chemistry involved in propellant combustion processes in micro-scale combustors for propulsion systems on micro-spacecraft. These spacecraft are planned to have a mass less than 50 kilograms with attitude control estimated to be in the 10 milli-Newton thrust class. These combustors are anticipated to be manufactured using Micro Electrical Mechanical Systems (MEMS) technology and are expected to have diameters approaching the quenching diameter of the propellants. Combustors of this size are expected to benefit significantly from surface catalysis processes. Miniature flame tube apparatus is chosen for this study because microtubes can be easily fabricated from known catalyst materials and their simplicity in geometry can be used in fundamental simulations for validation purposes. Experimentally, we investigated the role of catalytically active surfaces within 0.4 and $0.8 \mathrm{~mm}$ internal diameter microtubes, with special emphases on ignition processes in fuel rich gaseous hydrogen and gaseous oxygen. Flame thickness and reaction zone thickness calculations predict that the diameters of our test apparatus are below the quenching diameter of the propellants in sub-atmospheric tests. Temperature and pressure rise in resistively heated platinum and palladium microtubes was used as an indication of exothermic reactions. Specific data on mass flow versus preheat temperature required to achieve ignition are presented. With a plug flow model, the experimental conditions were simulated with detailed gas-phase chemistry, thermodynamic properties, and surface kinetics. Computational results generally support the experimental findings, but suggest an experimental mapping of the exit temperature and composition is needed.

14. SUBJECT TERMS

Chemical propulsion; Rocket engines; Low thrust propulsion; Spacecraft propulsion 15. NUMBER OF PAGES 20

\begin{tabular}{|c|c|c|}
\hline $\begin{array}{c}\text { 17. SECURITY CLASSIFICATION } \\
\text { OF REPORT }\end{array}$ & $\begin{array}{c}\text { 18. SECURITY CLASSIFICATION } \\
\text { OF THIS PAGE }\end{array}$ & $\begin{array}{c}\text { 19. SECURITY CLASSIFICATION } \\
\text { OF ABSTRACT } \\
\text { Unclassified }\end{array}$ \\
Unclassified & Unclassified
\end{tabular}

